\title{
A Study on the Coupling Evaluation of Higher Education Level and Economic Development at Urban Level in China
}

\author{
Chunguang Tang ${ }^{1, a}$ \\ ${ }^{1}$ School of Economics, Shanghai University, P.R. China \\ ashjrxytcg@163.com
}

Keywords: Higher education level; Economic development; Chinese cities; Coupling mechanism; Evaluation

\begin{abstract}
Based on the data of higher education level and economic development level of 31 large and medium-sized cities in China, an index system to measure the level of urban higher education and economic development is established. The coupling method in physics is introduced to explore the relationship between urban higher education and the coordinated development of economic level. The results show that there are great differences in the level of higher education and the level of economic development among different regions, and the progress of higher education level plays a more important role in promoting economic growth in economically backward areas. The development of higher education in developed regions is mainly reflected in the improvement and optimization of economic structure. In addition, for backward areas, the promotion of higher education, still plays an important role in narrowing the gap of regional economic development.
\end{abstract}

\section{Introduction}

In 2017, major cities in China began a new round of talent competition to attract high-end talents in order to gain an advantage in economic development. Neo-classicist economics believes that technological progress is the core driving force for long-term economic growth. The slowdown in China's economic growth has once again confirmed that the model of relying on increased capital investment to drive growth is unsustainable. The higher education not only trains the high quality labor force for the society, but also catalyzes the birth of the new technology. Therefore, it is of great practical significance to explore the role of higher education level in economic development and to examine the coordination between current higher education level and economic development.

The theory of modern economic growth regards technological progress as an important variable of economic growth. Solow confirms the contribution of education to economic development in the time of economic development [1]. Bluestone believes that higher education can produce more skilled labors in addition to its direct economic impact on the region. They can get higher pay for their work and thus contribute more taxes [2]. Stevenson 1994 and others have also done in-depth research in this field[3]. By making a comparative study of the contribution of higher education to economic growth in the eastern and western regions of China from 1990 to 2000, Song Huaming believed that the gap of human capital caused by the gap in the development of higher education is the main factor of the imbalance of regional economic development in the east and west regions [4].

\section{The Coupling Mechanism of Education System and Development System}

Coupling is a concept in physics. It refers to the phenomenon that two or more systems or modes of motion interact with each other and even unite through various interactions. They depend on each other under the benign interaction among subsystems. Dynamic correlation of coordination and mutual promotion.

This paper holds that there is a circular relationship between the level of higher education and the level of economic development. To evaluate the relationship between the level of higher education and economic development, we should comprehensively test the degree of coordination and mutual benefit between the two systems, and not only consider the role of education in 
economic development.

The relationship between the regional education system and the regional development system is: technological progress and human capital accumulation brought about by education promote economic development and improve the quality of regional development. At the same time, the level of development will also promote or restrict the development of education. Figure 2.1 describes the coupling mechanism between education system and development system, between the two systems are coupled directly or indirectly. It is through these coupling channels that the education system and the development system produce the coupling effect between the educational progress and the economic development to promote the economic development, which is related to each other and promotes each other.

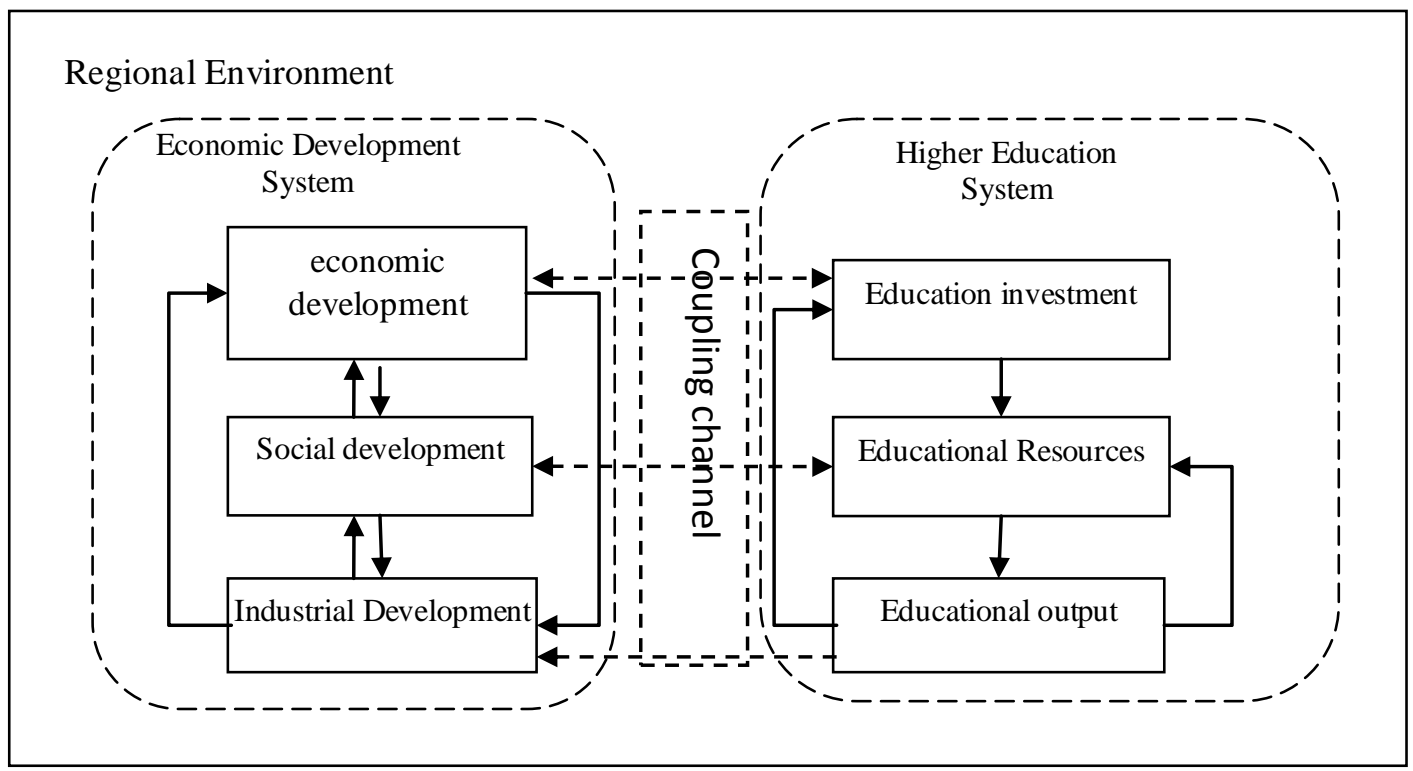

Figure 1 The Coupling Mechanism of Higher Education System and Economic Development System

\section{Empirical Analysis Based on the Urban Level of China}

Methods and Models. Research methods. Based on the above research logic and the coupling theory of physics, this paper adopts the coupling analysis method to evaluate the performance of the development of higher education in promoting regional economic development. In the process of demonstration, the coupling model is used to calculate the coupling degree and the coupling coordination degree between the two systems to reflect the promoting effect of the development of higher education on the economic development.

coupling model. Coupling function. By means of the concept of capacity coupling in physics and its capacity coupling function model, the interaction coupling degree model of multiple systems is obtained [5], that is:

$$
\mathrm{C}=\left\{\left(\mathrm{U}_{1} \mathrm{U}_{2} \cdots \mathrm{U}_{\mathrm{s}}\right) /\left[\Pi\left(\mathrm{U}_{\mathrm{i}}+\mathrm{U}_{\mathrm{j}}\right)\right]\right\}^{1 / \mathrm{s}}
$$

On this basis, the coupling model of regional "higher" education system and "development" system can be derived. The formula is as follows:

$$
\mathrm{C}=2\left\{\left(\mathrm{U}_{1}+\mathrm{U}_{2}\right) /\left[\Pi\left(\mathrm{U}_{1}+\mathrm{U}_{2}\right)\right]\right\}^{1 / 2}
$$

$\mathrm{C}$ is the coupling degree, and $0 \leq \mathrm{C} \leq 1$, the greater the $\mathrm{C}$ is, the higher the coupling degree is. The degree of coupling describes the degree of interaction between systems or elements, but it does not reflect the good or bad interaction between systems [6]. In order to overcome the limitation of coupling degree and reveal the coupling effect of innovation-driven development more objectively 
and accurately, the coupling coordination function is further introduced in this study. The formula is:

$$
\begin{aligned}
& \mathrm{D}=(\mathrm{C} \times \mathrm{T})^{1 / 2} \\
& \mathrm{~T}=\alpha \mathrm{U}_{1}+\beta \mathrm{U}_{2} \\
& \alpha+\beta=1
\end{aligned}
$$

Where $\mathrm{D}$ is the coupling coordination degree $0 \leq \mathrm{D} \leq 1$, the higher the value of $\mathrm{D}$ is, the better the effect of promoting each other is, the better the effect of educational progress on economic development. $\mathrm{T}$ is the comprehensive "efficacy" index of the educational system and the development system, which describes the degree of influence of the level of integrated development of the two systems on the degree of coupling and coordination; $\alpha$ and $\beta$ are the weights of the system to be determined. The contribution rate of education and development system to the coupling of the two systems is represented respectively.

Comprehensive development level function. It can be seen that the coupling degree depends on the number of systems participating in the coupling and the "comprehensive level of development" of each system from Eq.2. The "level of integrated development" is the synthesis of the contribution of all indicators in each system to the system, and the "level of integrated development" of the two systems of innovation and development systems can be achieved by adding an overall approach [14]. The formulas are as follows:

$$
\mathrm{U}_{\mathrm{s}}=\sum_{\mathrm{j}=1}^{\mathrm{n}} \mathrm{u}_{\mathrm{sj}} \mathrm{w}_{\mathrm{sj}}
$$

Among them, Usj is the contribution of the index of the $\mathrm{j}$ term to the efficiency of the s system, and Wsj is the weight of the index of the $\mathrm{j}$ term of the second system. At present, the main calculation methods of weight are Delphi (Delphi method), entropy method, coefficient of variation method and so on. In this paper, the entropy method is used to calculate the weight of each index, and the concrete steps are omitted here.

Construction of Empirical Index System. Based on the specific conditions and realistic features of the urban education system, an empirical index system for the evaluation of urban higher

\begin{tabular}{|c|c|c|}
\hline $\begin{array}{l}\text { First-level } \\
\text { indicators }\end{array}$ & $\begin{array}{l}\text { Second-level } \\
\text { indicators }\end{array}$ & Third-level indicators \\
\hline \multirow{7}{*}{$\begin{array}{l}\text { Higher } \\
\text { education }\end{array}$} & Educational & Number of colleges \\
\hline & Resources & Number of full-time teachers in colleges and universities (person) \\
\hline & \multirow{2}{*}{$\begin{array}{l}\text { Education } \\
\text { investment }\end{array}$} & $\begin{array}{l}\text { The amount of investment in science and education in fiscal expenditure } \\
\text { (ten thousand yuan) }\end{array}$ \\
\hline & & Social donation to education (10,000 yuan) \\
\hline & \multirow{3}{*}{$\begin{array}{c}\text { Educational } \\
\text { output }\end{array}$} & Number of patents granted (pieces) \\
\hline & & Number of scientific papers (papers) \\
\hline & & Number of graduates (person) \\
\hline
\end{tabular}
education including educational resources, educational input, and educational output was constructed(Table 1).

Table 1 Evaluation Index System of Higher Education Level

Similarly, based on the general evaluation of regional development level and the particularity of urban regional unit, this study constructs an empirical index system of urban development level evaluation from three secondary indicators of economic aggregate, industrial development and social development (Table 2). 
Table 2 Evaluation Index System of Urban Development Level

\begin{tabular}{|c|c|c|}
\hline $\begin{array}{l}\text { First-level } \\
\text { indicators }\end{array}$ & $\begin{array}{l}\text { Second-level } \\
\text { indicators }\end{array}$ & Third-level indicators \\
\hline \multirow{8}{*}{$\begin{array}{c}\text { economic } \\
\text { developme } \\
\text { nt }\end{array}$} & Economic & Per capita regional production (ten thousand yuan) \\
\hline & aggregate & Tertiary industry GDP ratio $(\%)$ \\
\hline & & Output value of industrial enterprises above designated size (ten thousand \\
\hline & Industrial & yuan) \\
\hline & Development & $\begin{array}{l}\text { Total sales of commodities above designated size in wholesale and retail } \\
\text { trade (million yuan) }\end{array}$ \\
\hline & \multirow{3}{*}{$\begin{array}{c}\text { Social } \\
\text { development }\end{array}$} & Per capita disposable income of urban residents (yuan) \\
\hline & & Import and export of goods (ten thousand US dollars) \\
\hline & & Number of hospital beds \\
\hline
\end{tabular}

Empirical analysis. This study excludes cities where data are not available. Specific evaluation results are shown in table 3.

Table 3 Coupling evaluation results of some cities in China

\begin{tabular}{cccccccccccc}
\hline City & $\mathbf{U}_{\mathbf{1}}$ & $\mathbf{U}_{\mathbf{2}}$ & $\mathbf{U}_{\mathbf{1}} / \mathbf{U}_{\mathbf{2}}$ & $\mathbf{C}$ & $\mathbf{D}$ & $\mathbf{C i t y}$ & $\mathbf{U}_{\mathbf{1}}$ & $\mathbf{U}_{\mathbf{2}}$ & $\mathbf{U}_{\mathbf{1}} / \mathbf{U}_{\mathbf{2}}$ & $\mathbf{C}$ & $\mathbf{D}$ \\
\hline BeiJing & 0.8887 & 0.7546 & 1.1776 & 0.9967 & 0.9049 & ChangSha & 0.1015 & 0.1336 & 0.7591 & 0.9906 & 0.3412 \\
ShangHai & 0.4888 & 0.7545 & 0.6479 & 0.9769 & 0.7793 & JiNan & 0.0888 & 0.1437 & 0.6176 & 0.9717 & 0.3361 \\
ShenZhen & 0.2689 & 0.4769 & 0.5638 & 0.9603 & 0.5984 & XiaMen & 0.0502 & 0.2003 & 0.2508 & 0.8008 & 0.3167 \\
GuangZhou & 0.1913 & 0.4120 & 0.4643 & 0.9307 & 0.5298 & HaErBin & 0.0962 & 0.0967 & 0.9950 & 1.0000 & 0.3105 \\
TianJin & 0.2181 & 0.3519 & 0.6198 & 0.9721 & 0.5264 & ChangChun & 0.0830 & 0.1037 & 0.8005 & 0.9938 & 0.3046 \\
HangZhou & 0.2238 & 0.2566 & 0.8723 & 0.9977 & 0.4895 & HeFei & 0.0717 & 0.1095 & 0.6550 & 0.9780 & 0.2977 \\
NanJing & 0.1966 & 0.2544 & 0.7730 & 0.9918 & 0.4729 & FuZhou & 0.0511 & 0.1497 & 0.3417 & 0.8714 & 0.2958 \\
ChengDu & 0.1716 & 0.2336 & 0.7346 & 0.9882 & 0.4475 & ShiJiaZhuang & 0.0539 & 0.0873 & 0.6179 & 0.9717 & 0.2619 \\
WuHan & 0.1869 & 0.2079 & 0.8993 & 0.9986 & 0.4440 & TaiYuan & 0.0511 & 0.0825 & 0.6194 & 0.9720 & 0.2548 \\
ChongQing & 0.1454 & 0.2554 & 0.5693 & 0.9616 & 0.4390 & NanChang & 0.0508 & 0.0643 & 0.7898 & 0.9931 & 0.2390 \\
DaLian & 0.1655 & 0.2093 & 0.7907 & 0.9931 & 0.4314 & NanNing & 0.0254 & 0.0811 & 0.3126 & 0.8519 & 0.2130 \\
NingBo & 0.1383 & 0.1900 & 0.7278 & 0.9875 & 0.4026 & LanZhou & 0.0445 & 0.0421 & 1.0576 & 0.9996 & 0.2081 \\
XiAn & 0.1697 & 0.1465 & 1.1583 & 0.9973 & 0.3971 & WuLuMuQi & 0.0197 & 0.0675 & 0.2919 & 0.8364 & 0.1910 \\
QingDao & 0.0978 & 0.2120 & 0.4611 & 0.9295 & 0.3794 & GuiYang & 0.0246 & 0.0471 & 0.5220 & 0.9494 & 0.1844 \\
ShenYang & 0.1029 & 0.1774 & 0.5802 & 0.9641 & 0.3676 & YinChuan & 0.0082 & 0.0446 & 0.1837 & 0.7241 & 0.1383 \\
ZhenZhou & 0.0832 & 0.1801 & 0.4620 & 0.9298 & 0.3499 & & & & & & \\
\hline
\end{tabular}

Comprehensive Level Analysis. Whether from the level of higher education or the level of economic development, the differences between cities in China are very significant. In the aspect of education level ( U1 ), the highest is Beijing, the lowest city is Yinchuan; In terms of development level ( U2 ), the highest is still in Beijing, and the lowest city is Lanzhou. From the comparative analysis of education level and development level, most cities in China are in the leading stage of development and innovation. The empirical data show that only three cities in Beijing, Xi'an and Lanzhou is the leading educational level. Among them, Beijing not only performs well in development, but also surpasses development level in education. Xi'an development is in the middle of the level, but its education level is relatively high. This is closely related to the dense distribution of universities, scientific research institutions and military enterprises in Xi'an. Lanzhou is relatively special, its development ability and the development level are relatively low, but its education level leads the development level. Lanzhou is an important node city of China's western higher education network, which will play an important role in promoting the level of higher education in the northwest of China.

Coupling Evaluation Analysis. In terms of $\mathrm{C}$ value, there is little difference in $\mathrm{C}$ value in 31 cities, almost all of them are above 0.9 . This shows that at the urban level, the interaction between education and economic development is very significant. The $\mathrm{D}$ value difference of 31 cities is very significant. The highest was Beijing 0.9049, and the lowest was Yinchuan 0.1383. This shows that there are significant differences in the performance of different cities in terms of the relationship 
between education promoting economic development and the relationship between development and educational progress. The D value of 31 cities basically shows the characteristics of ladder distribution. In the first step are Beijing, Shanghai, Guangzhou, Shenzhen and Tianjin, whose D values are above 0.5. In particular, education and development in Beijing and Shanghai are mutually promoted, coordinated and far ahead of others. More than half of the cities are densely distributed in the second step with $\mathrm{D}$ values ranging from 0.3 to 0.5 . The remaining 10 cities are located on the third ladder, with the worst performers being Urumqi, Guiyang and Yinchuan. The five cities with the highest degree of coupling and coordination are all located in the most developed eastern coastal areas. The second tier of cities are basically developed cities in the east and regional core cities in some central and western regions. The third ladder cities are mostly central and western cities.

\section{Conclusions and Policy Implications}

First, there are huge spatial differences in both the level of higher education and the level of economic development in Chinese cities. The eastern cities are obviously ahead of the central and western cities in the level of higher education and the level of development. Second, at present, most of the cities in China are in the stage of leading the level of higher education in the development level. This indicates that the effect of higher education in most cities on promoting economic development is not obvious. There is still a long way to go to realize the economic development driven by higher education. Third, the correlation and interaction between education and development are very significant. This is also an objective realistic basis for cities to promote the development of higher education and gather high-end talents. Fourth, in contrast to the coupling degree, there are great differences in the coupling and coordination degree among the 31 large and medium cities. This shows that different cities in education and development in coordination with each other to promote efficiency gap. Cities with low degree of coupling and coordination should actively straighten out the relationship between innovation and development, implement innovation-driven development strategy according to local conditions, and realize the promotion of the relationship between innovation and development system from antagonistic running-in stage to coordination and promotion stage.

\section{References}

[1] Solow, Robert M, A Contribution to the Theory of Economics Growth. Quarterly Journal of Economics, 1957,109(2):1-20.

[2] Bluestone, B. An Economic Impact Analysis. Boston: John W. Mc Cormack Institute of Public Affairs. The University of Massachusetts.1993(1).

[3] Stevens, D.W. The Economic Value of the University of Maryland system. Baltimore: The Jacob France Center. Merrick School of Business, University of Baltimore, 1994(4).

[4] Song Huaming. Comparative study on the contribution of higher Education to the Economic growth rate of Eastern and Middle West regions. Social Science 7: 11-16.

[5] Wang Qi. Study on Spatial Coupling Mechanism of Industrial Cluster and Regional economy. Changchun: northeast normal University. 2008: 56-57.

[6] Gao Nan, Ma Yaofeng, Li Tianshun, et al. A study on the spatio-temporal differentiation of the coupling relationship between inbound tourism and import trade in China from 1993 to 2010. Economic Geography 32 32: 143-148. 